\title{
Dois livros de teatro
}

\author{
Mariangela Alves de Lima
}

\section{A Vertigem das Máscaras}

Primeiro volume de uma coleção, Henrique IV e Pirandello oferece aos leitores uma oportunidade de conhecer, através de uma excelente tradução de Aurora Bernardini e Homero Freitas de Andrade, um dos textos axiais para a criação dramatúrgica e para as práticas de encenação deste século. A representação dentro da representação será, de Pirandello a Genet, uma das mais caras obsessões do teatro.

Para enfrentar a complexidade dos problemas que este Henrique $I V$ faz vir à tona, há um ensaio introdutório planejado como um "roteiro para uma leitura". Acompanhando os passos do roteiro o leitor pode identificar o tema central da obra de Pirandello, o tema que o transformou em adjetivo. "Pirandelliano" é o qualificativo que sintetiza a alternância ou a superposição de máscaras até que se instaure a dúvida sobre a verdadeira raiz do ser.

Aurora Fornoni Bernardini vincula esse problema central na obra de Pirandello ao meio sociocultural onde se formou. Ao acanhado código de ética de uma província italiana do século XIX correspondem os subprodutos preconceito e hipocrisia. Dessa sufocante vivência pequeno-burguesa Pirandello extrairá um drama essencial que se desdobra e refina ao longo de sucessivas representações. Será, sem desejar, "um escritor marcado pelo peso dos mesmos preconceitos que tecem os destinos dos dramas antigos e formam o fundo da psicologia popular, de sua justiça e de suas leis obscuras".

Mesclando-se a informações biográficas, as etapas subseqüentes do roteiro mostram como as criações do autor se aguçam para isolar e aprofundar um tema predominante. Quando, nas obras, se aclara a fratura entre um "eu" nebuloso e sucessivas aparências, Pirandello se encaminha para o teatro. $O$ teatro surge como um meio para desacomodar o que já foi enunciado, para evidenciar que há, no interior do indivíduo, uma crise, um dinamismo irresolvido entre ser e parecer.

No momento em que assinala a passagem da literatura para o palco, o ensaio de Au'rora Fornoni Bernardini realiza sua contribuição mais sensível e pessoal: "À medida que o indivíduo, porém, começa a ter consciência do caráter multiforme e contraditório de sua verdade e a procurar-se na imagem que os outros fazem dele, desafiá-la e provarse e ver-se viver, estamos chegando à Personagem e ao mundo do teatro, no dizer de muitos críticos, a verdadeira dimensão de Pirandello". O que se discute intensamente nas esferas mais abstratas da filosofia ou da psicologia torna-se um material privilegiado para o drama, um problema humano confundido com a essência do jogo teatral. É a visibilidade da máscara teatral que torna visível as outras máscaras sociais.

Três peças são avocadas (Henrique IV, Seis personagens e Encontrar-se) para ilustrar as nuances de rejeição ou adoção desse vertiginoso jogo de aparências. Considerando os limites impostos à extensão de um ensaio introdutório, a autora lamenta não ter podido referir-se a outras obras igualmente importantes da vasta produção pirandelliana.
MARIANGELA ALVES DE LIMA é critica de teatro do "Caderno 2" de O Estado de S. Paulo.

Henrique IV e Pirandello, Aurora Fornon Bernardini. Săo Paulo, Éditora da Universidade de Săo Paulo, 176 pp.

Grupo Macunalma: carnavalizaçăo e mito, David George. São Paulo, Editora Perspectiva, 154 pp.

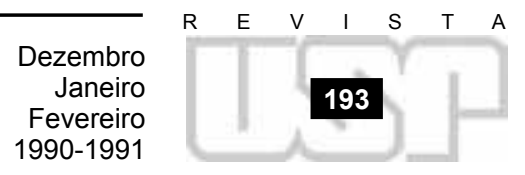


$\mathrm{Na}$ verdade esse zelo abrangente - quase irresistível quando se trata de um autor escolhido por afinidade - atrapalha um pouco a fluência deste roteiro. Sem dúvida o leitor chegará a Henrique $I V$ bem provido de informaçōes básicas sobre a obra e a vida de Pirandello. Entretanto esse percurso é recortado por citações de contos, peças e críticas que convergem sempre para esse núcleo de dissociação entre essência e aparência.

Talvez fosse mais produtivo o método inverso, ou seja, fazer derivar de Henrique IV - experiência integralmente acessível ao leitor - os elementos críticos que o ensaio vai desvendando com o auxílio de outras obras. A partir da localização desses elementos na peça incluída no volume seria possível mencionar obras que contrastam, relativizam ou aprofundam os mesmos problemas.

Vejamos, a título de exemplo, a conclusão do capítulo "Política e poética": “O 'drama' que desenvolvem as personagens pirandellianas independe de sua origem e de suas conotações histórico-sociais, conseguindo alcançar uma verdade de parábola que o coloca além da história. A personagem pirandelliana, porem, reconhece e define 'os outros' e os caracteriza tão bem que a sua acusação acaba se concretizando em crítica social e análise psicológica, das mais incisivas e contundentes".

Esta é uma observação extremamente importante para orientar uma aproximação da obra de Pirandello porque, além de situá-lo corretamente em meio ao tumulto das definições estético-políticas do seu tempo, desvenda um procedimento singular no enfrentamento do social e do histórico.

Henrique IV ê um campo privilegiado para fundar essa observação. Nesta peça, mais do que em outras, é visível a apropriação metafórica da história. E, sob a luz desse comentário de Aurora Fornoni Bernardini, pode-se constatar na peça em que medida o protagonista, aparentemente perdido na vertigem de máscaras sucessivas, é capaz de reconhecer nas máscaras alheias um mecanismo introjetado no social. A contigüidade entre a apreciação crítica e a obra poderia sugerir ao leitor uma forma de abordar por conta própria outras criaçōes de Pirandello.

\section{O CPt e o Teatro Paulista}

Desde 1978 o Grupo Macunaíma, agora núcleo de encenação do Centro de Pesquisas Teatrais do SESC, ocupa um lugar frontal

na cena brasileira. A qualidade de seus espetáculos garante-lhe uma fortuna crítica ímpar no Brasil e em outros países onde eventualmente se apresenta. O processo de trabalho do CPT e a estética peculiar que vem se definindo através de um conjunto de espetáculos reaparecem influenciando outros conjuntos que tomam como modelo os seus procedimentos ou as suas encenações.

Grupo Macunatma: carnavalização e mito, de David George, é um estudo sobre a definição conceitual do grupo e os resultados cênicos que apresentou ao público de 1978 a 1986 . Foram excluídas desse ensaio as encenações produzidas pelo Centro de Pesquisas, pautadas por um método único de formação de atores mas assinadas por outros diretores, e não por Antunes Filho. Romeu e Julieta, espetáculo dirigi- 
do por Antunes Filho, é apenas mencionado. No prefácio, Sábato Magaldi explica que o autor está interessado apenas na "adaptação/encenação de autores brasileiros".

O livro é portanto um recorte da extensa realidade que o CPT vem criando quando forma atores e cenógrafos, organiza cursos para a formação de público, experimenta espetáculos que não chega a apresentar publicamente e apresenta encenações realizadas por pessoas formadas dentro do núcleo de estudo e pesquisa.

Firmemente plantado no estudo de três encenações, David George se apóia no trabalho artístico para iluminar a base conceitual que sustenta a ampla arquitetura do CPT. Encontra na produção cênica do Grupo Macunaíma uma correspondência histórica com o Modernismo. E não sem razão. Oswald de Andrade será o nume tutelar do Oficina (relação que o autor examina em outro livro), cabendo a Mário de Andrade insuflar o espirito macunaŕmico no teatro do CPT. A encenação de Macunaíma, em 1978, não é apenas a transposição cênica de uma obra, mas também da contribuição crítica de Mário de Andrade para a compreensão da cultura brasíleira. Para pôr em cena o imaginário e o dinamismo das forças subterrâneas da cultura o espetáculo recorria a procedimentos de Mário de Andrade, notadamente à dissolução das antinomias arcaico/moderno, rural/urbano e selvagem/europeu.

Antes de apontar no espetáculo Macunaima os signos que exteriorizam uma abordagem cultural de fundo modernista, o autor recorre ao conceito de "carnavalização", exemplificado por uma aproximação entre a épica camoniana e a "rapsódia" de Mário de Andrade. Situada em uma relação intertextual a saga do "herói sem nenhum caráter" seria uma paródia, instrumento para libertar a arte moderna do peso dos seus maiores.

$\mathrm{Na}$ verdade essa laboriosa comparação entre Macunatma e Os Lusíadas é inútil para ampliar horizontes críticos. Os estudos citados pelo autor (Cavalcanti Proença, Haroldo de Campos e Gilda de Mello e Souza) e as reflexões de Mário de Andrade sobre as suas criações aclaram suficientemente o assunto. Trata-se, sem dúvida alguma, de umá apropriação paródica ou irônica de temas e gêneros consagrados. Mas há uma irrisão simbólica do monumental, e não apenas do monumental específico de uma cultura. Basta verificar que as críticas do espetáculo Macunatima em outros parses - onde os críticos nunca perpetraram a análise sintática de Os Lusladas - reconhecem o parentesco do herói com Peer Gynt ou com D. Quixote.

Não acrescenta muito perguntar se Mário de Andrade teve ou não a intenção de parodiar Os Lustadas. De qualquer forma, depois de completar essa liça, David George serve-se do gênero épico para deslindar, com muito proveito, os entrelaçamentos entre mito e história que constituem a viga mestra dos espetáculos encenados por Antunes Filho. Reconhece na primeira encenação do grupo conceitos e imagens que migram para trabalhos posteriores e que gradualmente se despem da ironia: a viagem, o tempo circular, a celebração da utopia e a reintegração dos heróis ao cosmos.

Por outro lado a idéia de "carnavalização" permite demonstrar que a estrutura épica
Cena de despedida de

A hora e vez de Augusto

Matraga, montagem do

Grupo Macunaíma, 1987 
Ao acanhado código de ética de uma província italiana do século XIX correspondem os subprodutos preconceito

e hipocrisia. Dessa sufocante vivência pequeno-burguesa Pirandello extrairá um drama essencial que se desdobra e refina ao longo de sucessivas apresentações. Será, sem desejar, "um escritor marcado pelo peso dos mesmos preconceitos que tecem os destinos dos dramas antigos e formam o fundo da
psicologia popular..."

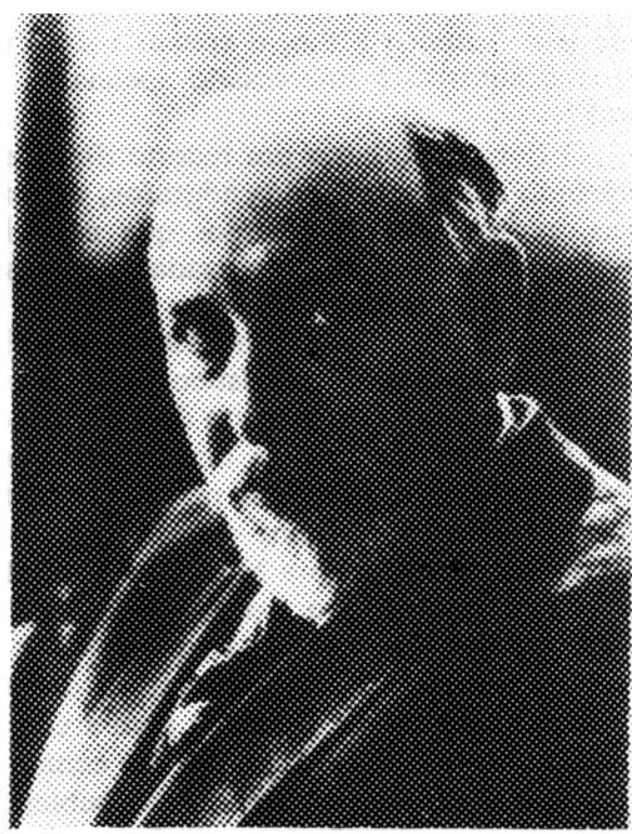

é necessária para criar o seu anverso. Permite reconhecer gêneros constantes e divergentes onde são possíveis a humanização da personagem, o sincretismo entre o real e o maravilhoso, a degradação fertilizadora do estilo e a apropriação estética do corpo. Finalmente "o espiritual é degradado e degradar significa devorar para renovar, destruir para regenerar".

Assim preparado o leitor chega à melhor parte do livro, a análise das encenações. Por várias razões que não caberiam aqui, as aproximações fenomenológicas do espetáculo teatral são raras em nossa bibliografia. É um prazer especial encontrar um ensaio em que o autor enfrenta um a um os diferentes elementos de composição da linguagem teatral, sem alterar seu delicado equilíbrio. David George reconstrói com rigor a memória visual e auditiva de três espetáculos do Grupo Macunaíma, associando a percepção ao sentido.

O mesmo procedimento é aplicado aos três espetáculos, embora em cada um o relevo dos elementos de composição se altere em função da aproximação crítica. Em Macunaíma a estrutura narrativa ocupa o primeiro plano onde se introduzem as explicitações sobre as fontes históricas que deram origem às imagens.

Nelson 2 Rodrigues, um espetáculo que recorreu na sua feitura a Jung e a Mircea Eliade, é observado primordialmente pelas relações que estabelece no plano de luz. Embora trate acuradamente do uso do espaço, da organização cinematográfica da narrativa e das referências sonoras, David George se concentra nas cores, na intensidade e nas formas criadas pela luz, um elemento expressivo privilegiado para significar a atemporalidade e as imagens, recorrentes na cultura, do sagrado e do profano.

Em Augusto Matraga, espetáculo encenado em 1986, o autor observa a inspiração no imaginário e nos ritos cristãos. A procissão (ação humana) e o presépio (figuração do mundo) são isolados pelo trabalho crítico e, em seguida, atravessados pelo movimento dramático dos Evangelhos: Advento, Paixão, Morte e Ressurreição. Os elementos singulares de uma cultura são, a cada momento da análise, associados a essa aspiração transcendental da encenação.

À guisa de conclusão o livro inclui informações resumidas sobre o moderno teatro brasileiro. Desculpando-se previamente o autor apresenta Os Comediantes como único grupo carioca realmente significativo dessa modernidade. Conjuntos importantes são apenas mencionados porque "trata-se de livros a serem escritos".

O relevo atribuído ao teatro paulista é inevitável para um pesquisador estrangeiro, obrigado a calçar-se sobretudo em fontes bibliográficas. E a historiografia do teatro paulista tem sido, sobretudo nestas duas últimas décadas, bem mais prolífica do que a de outros estados. Por essa razão talvez seja melhor reconhecer que estamos sofrendo de um estreitamento que torna a nossa visão do teatro menos do que paulistú, apenas paulistana. 